\title{
Identifying some determinants of "jet lag" and its symptoms: a study of athletes and other travellers
}

\author{
J Waterhouse, B Edwards, A Nevill, S Carvalho, G Atkinson, P Buckley, T Reilly, \\ R Godfrey, R Ramsay
}

Background: Travelling across multiple time zones disrupts normal circadian rhythms and induces "jet

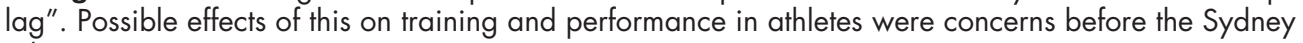
Olympic Games.

Objective: To identify some determinants of jet lag and its symptoms.

Methods: A mixture of athletes, their coaches, and academics attending a conference $(n=85)$ was studied during their flights from the United Kingdom to Australia (two flights with a one hour stopover in Singapore), and for the first six days in Australia. Subjects differed in age, sex, chronotype, flexibility of sleeping habits, feelings of languor, fitness, time of arrival in Australia, and whether or not they had previous experience of travel to Australia. These variables and whether the body clock adjusted to

See end of article for authors' affiliations

Correspondence to:

Dr Waterhouse, Research Institute for Sport and

Exercise Sciences,

Liverpool John Moores

University, Trueman

Building, Henry Cotton

Campus, 15-21 Webster

Street, Liverpool L2 2ET,

UK; waterhouseathome@

hotmail.com

Accepted 23 July 2001 new local time by phase advance or delay were tested as predictors for jet lag and some of its symptoms by stepwise multiple regression analyses.

Results: The amount of sleep in the first flight was significantly greater in those who had left the United Kingdom in the evening than the morning (medians of 5.5 hours and 1.5 hours respectively; $\mathrm{p}=$ 0.0002 , Mann-Whitney), whereas there was no significant difference on the second flight (2.5 hours $\checkmark 2.8$ hours; $p=0.72$ ). Only the severity of jet lag and assessments of sleep and fatigue were commonly predicted significantly $(p<0.05)$ by regression analysis, and then by only some of the variables. Thus increasing age and a later time of arrival in Australia were associated with less jet lag and fatigue, and previous experience of travel to Australia was associated with an earlier time of getting to sleep. Subjects who had adjusted by phase advance suffered worse jet lag during the 5 th and 6th days in Australia.

Conclusions: These results indicate the importance of an appropriate choice of itinerary and lifestyle for reducing the negative effects of jet lag in athletes and others who wish to perform optimally in the new time zone.
A rapid transition across time zones leads to the transient appearance of a number of undesirable side effects, collectively known as "jet lag". ${ }^{1-8}$ They include: difficulties with initiating and maintaining sleep during the new night time by local time; a general fatigue and loss of motivation and the ability to concentrate in the new daytime; decreased interest in food and loss of appetite; altered bowel function. These effects are attributed to a transient desynchrony between the new local time and the endogenous circadian oscillator, the "body clock". In a previous set of studies, "we investigated the relations between these variables in a group of subjects who had flown from the United Kingdom to Australia (10 time zones to the east).

We now consider variables that may predict the extent of the difficulties experienced by the subjects who had undertaken this journey. The subjects included elite athletes (preparing for the 2000 Olympic Games in Sydney), their coaches and other officials of "Team GB", and academics attending a scientific conference on sport. They varied considerably in their age, self rated fitness, and tasks once in Australia, but all had busy schedules.

Evidence from the literature on possible predictors is comparatively scarce (but see Kerkhof ${ }^{10}$ and Harma ${ }^{11}$ for reviews), and few field studies of this area appear to have been carried out. Those studies that do exist indicate that there may be more difficulties for women, because of irregularities of the menstrual cycle, ${ }^{12}{ }^{13}$ and that older travellers may be at a disadvantage compared with younger ones. ${ }^{14}{ }^{15}$ Laboratory studies and theoretical considerations also suggest that older subjects and those whose habits are more rigid, or who are less able to ignore feelings of fatigue, may be at a disadvantage. ${ }^{16-18}$ In addition, if the body clock were to adjust from United Kingdom to Australian local time by an advance of the circadian system $(+10$ hours $)$, the advantage would be with the "morning type" or "lark". ${ }^{19-21}$

In practice, however, the position would be more complex if it depended on some aspects of the flight itself (time of departure from the United Kingdom and arrival in Australia), the subject's experience of such a journey, and activities once in Australia. As an example of this last possibility, it may be that the elite athletes would be far less prepared than other subjects to allow jet lag to undermine such an opportunity.

Taking all these possibilities into consideration, the following possible predictors of jet lag and its associated symptoms have been considered. For each, we outline also a possible interpretation of any significant and reliable predictive power that may be found.

- Sex. Differences may be related to problems with the menstrual cycle (see above) or to a "macho" image.

- Age. Older subjects may be less flexible or they may be better able to "pace themselves". ${ }^{17}$

- Chronotype. "Morning types" would have less difficulty in phase advancing their body rhythms than "evening types", and vice versa, if adjustment were by phase delay. ${ }^{20} 22$

- Flexibility $v$ rigidity of sleep habits and languidness $v$ vigorousness. Immediately after arrival in Australia, normal patterns of sleep and activity will have been disrupted by the flights, and the effects of this will continue for some days until phase adjustment of the body clock has taken place. 
Those with greater flexibility of sleeping habits and those who can throw off feelings of fatigue during the daytime would be at an advantage. ${ }^{16} 23$

- Fitness. Several studies ${ }^{24-27}$ indicate that increased physical activity enables travellers to adjust more quickly to an altered sleep-wake schedule or maintain a robust restactivity rhythm. Although this observation predicts that athletes would suffer less from jet lag and its associated symptoms than non-athletes, the fact that the schedules of the athletes are more rigorous and they place such a high priority on top grade performance may mean that they would notice smaller decrements more and would be more anxious about them.

- Experience of travel to Australia. The behaviour of those who have travelled to Australia previously and know at first hand the kind of problems entailed may differ from those travelling to Australia for the first time, for whom any such difficulties may be less important than the new experiences that the trip offers.

- Time of arrival in Australia. The flight to Australia from the United Kingdom (with a one hour stopover in Singapore, taking a total of about 24 hours) left in the morning or evening. After a morning departure from the United Kingdom, subjects would arrive in Australia in the afternoon, on local time, and would first go to sleep at night after having been awake for about 30-35 hours. The flight before the stopover would have coincided with daytime in the United Kingdom, and the flight after the stopover would have coincided with daytime in Australia-that is, much of the flight would have been in daylight hours. By contrast, those departing from the United Kingdom in the evening would arrive in Australia early in the morning (about 0600). Subjects may take a nap on arrival at their hotel but, by the time that they would next go to bed at night, it would have been about 50-55 hours since their last full sleep in the United Kingdom. The flight before the stopover would have coincided with United Kingdom night time, and the one after it would have coincided with night time in Australiathat is, much of the flight would have been in darkness.

- Direction of adjustment. If, on arrival in Australia, the body clock is still adjusted to United Kingdom time, minimum mental and physical performance would occur at about 1500 local time, corresponding to 0500 United Kingdom time. It can be estimated that a phase advance of the body clock of 10 hours and a phase delay of 14 hours would both take about seven days to achieve. ${ }^{28}$ Whether an advance or delay took place would depend, at least partly, on the lightdark exposure of the subject in Australia. ${ }^{6}$ Light until about 1300 local time would promote a phase delay of the body clock, and light after about 1500 local time, a phase advance. If adjustment were by phase advance, the time of worst performance would, over the course of several days, advance through the afternoon and then through the morning; this may be very noticeable to a person trying to perform efficiently during the daytime. By contrast, if adjustment were by phase delay, then the time of worst performance would delay through the afternoon and then through the evening; in this case, the decrement may be less noticed after a few days when it became coincident with evening relaxation.

In practice, more than one of the above variables may act as a significant predictor, and different predictors may be more important at different stages of the process of adjustment. For example, effects related to the flights themselves would be most pronounced in the first day or so in Australia, whereas those associated with the direction of phase adjustment may become more apparent only after a few days.

In summary, we have investigated the value of several variables as predictors of the severity of jet lag and its symptoms in a group of subjects who shared a high motivation to perform as well as possible, and who had flown from the United Kingdom to Australia, an eastwards flight across 10 time zones.

\section{METHODS \\ Subjects}

Eighty five subjects were studied in total, of whom 54 were men. For the purposes of analysis (see below), men were given a score of 1 and women a score of 0 . The mean (SEM) age of the subjects was 32.1 (13.0) years. Fifty one were athletes, 18 trainers or administrators, and 16 were academics attending a scientific conference on sport. It will be noted that previous studies have tended to use mainly academics or sedentary travellers.

Before taking part in the study, all subjects had the aims and procedures explained to them. Any questions they had were then answered, and they signed consent forms. The protocol had been approved by the home institution's human ethics committee.

\section{Data collection before departure from the united kingdom}

In the weeks before departure, the following data were collected.

(1) Personal data. Apart from the information summarised above, subjects were asked to state if they had previously flown to Australia. If they had, they were given a score of 1 ; if not, a score of 0 . They were also asked to record details of their forthcoming flights. In total, the flights took about 24 hours. About one third of the subjects left the United Kingdom in the evening (local time) and arrived in Australia in the early morning, about 0600 (local time); they were called group 0 and given a score of 0 . The rest of the subjects left the United Kingdom in the morning and arrived in Australia in the late afternoon; they were called group 1 and given a score of 1 .

(2) Fitness. This was estimated from a questionnaire, ${ }^{29}$ and took into account the age of the subject. A score between 1 (least fit) and 5 (most fit) was awarded.

(3) Chronotype. This was estimated by the Composite Morningness Questionnaire of Smith et $a^{30}$; the higher the score, the greater the degree of "morningness". The results from this questionnaire indicated that seven subjects were "morning type", one was "evening type", and 77 were "intermediate type".

(4) Languidness/vigorousness and flexibility/rigidity of habits. These were estimated from the Circadian Type Inventory of Folkard et al. ${ }^{16}$ In each case a score was given, and the higher the score, the greater the amount of languor or flexibility of habits respectively.

Table 1 gives a summary of the personal information and results from these questionnaires.

\section{Data collection during the flights}

In all cases, there was a stopover of about one hour in Singapore, and the total time spent travelling was about 24 hours. During the flights, subjects were free to choose how they spent their time. Apart from those on the first flights associated with this study, subjects were required to keep a record of the amount of time spent asleep, both before and after the stopover. A total of 32 subjects from group 0 and 25 from group 1 carried out this part of the study.

Subjects who left the United Kingdom in the evening arrived in Australia at about 0600 by local time; those leaving the United Kingdom in the morning arrived in the afternoon by local time. Many of those arriving in the early morning had a brief nap on arrival at their hotel, but they had been advised against having a full sleep at this time (even though it coincided with night time in the United Kingdom). This was 
Table 1 Characteristics of the 85 subjects that were used as potential predictors of jet lag

\begin{tabular}{ll}
\hline Characteristic & Value \\
\hline Age (years) & $32.1(13.0)$ \\
Chronotype & $36.6(5.3)$ \\
Languidness & $41.0(6.3)$ \\
Flexibility & $44.3(8.0)$ \\
Fitness & $4.4(1.0)$ \\
Sex & \\
$\quad$ Female & 31 \\
$\quad$ Male & 54 \\
Flight arrival time & \\
$\quad$ Morning & 59 \\
Evening & 26 \\
Experience of travel to Australia & \\
$\quad$ None (given a score of 0) \\
$\quad$ One or more previous occasions (given a \\
score of 1) \\
Direction of phase adjustment \\
$\quad$ Advance (given a score of + +1 ) \\
$\quad$ Delay (given a score of -1 ) \\
$\quad$ Unclear (given a score of 0) \\
\hline
\end{tabular}

Where applicable, values are mean (SEM).

because a long sleep at this time might act as an "anchor sleep", ${ }^{31}$ although the subjects were told that it was because a long sleep would decrease the possibility of sleeping well their first night in Australia.

\section{Data collection after arrival in Australia}

Data were collected for the first six days in Australia, defining the day of arrival as day 1 ; for those subjects who did not arrive until the afternoon (see above), this meant that results from the early part of day 1 were missing. The first nocturnal sleep in Australia (which took place at the end of the arrival day) was called day 2, because questions about it were answered at the beginning of the second day; for this reason, sleep was recorded only from day 2 to day 6.

There were two types of data collection: responses to the questionnaire on jet lag and its symptoms, and measurements of tympanic temperature (Genius 1000, Sherwood, Nottingham, UK).

\section{Jet lag}

A questionnaire for studies in the field of jet lag and its associated symptoms has been developed, and details of this have been published previously. ${ }^{932}$ Briefly, subjects responded to a series of questions, using visual analogue scales. The responses to questions about the following were analysed in this study: the amount of jet lag; the amount of fatigue; sleep (the time of getting to sleep, the ease of getting to sleep, the ease of staying asleep, the time of waking up, alertness 30 minutes after rising); meals (hunger before a meal, enjoyment of the food, satiety after the meal); bowel function (frequency of movement, looseness of the faeces).

Most of the visual analogue scales had the same format, namely a line divided into 10 parts with the centre being labelled 0 and the extremes, +5 and -5 . In addition, these three points were labelled with brief descriptions of the sensations to be associated with them, from "much less than normal" $(-5)$, through "normal" $(0)$ to "much more than normal" $(+5)$. Modifications to this general scheme were as follows: for jet lag, the extremes of the scale were labelled 0 (no jet lag) and 10 (very severe jet lag); for times of retiring and rising, the extremes were -5 (much earlier than normal) and +5 (much later than normal), with 0 (normal) in the centre; for satiety, the extremes were -5 (still very hungry) and +5 (very bloated), with 0 (normal) in the centre.

Not all questions were given at each test time. The times when the subjective assessments were required were as follows: jet lag, 0800, 1200, 1600, 2000, 2400; sleep, 0800; fatigue, 0800, 1200, 1600, 2000, 2400; meals, 1200, 1600; bowel activity, 2400.

Before the journey, subjects were shown the questionnaire so that they could become familiar with its contents and the way to record their answers. Specific advice about the meaning of jet lag or any of the other questions in the questionnaire was not given.

\section{Tympanic membrane temperature}

Tympanic membrane temperature was used as an estimate of core body temperature and the phase of the body clock during the first six days in Australia. The temperature was measured in subjects seated indoors on three to five occasions a day, these being spread as evenly as possible throughout the waking period, subject to the activities of the subject. Measurements were not taken if the subject had been exercising during the previous 30 minutes, to minimise the direct effect of activity on core temperature. ${ }^{33}$

\section{Calculations and statistical analyses \\ Direction of phase adjustment}

The tympanic temperatures from each day were cross correlated with normative data for the circadian rhythm of core temperature obtained from the literature. ${ }^{5}$ The shift of the subject's temperature rhythm on each day was assessed by finding the shift of the temperatures that gave the highest positive correlation with the normative data. Consideration of all six days enabled a decision to be made as to whether adjustment of the circadian rhythm of core temperature to Australian time had been by phase advance or delay. This assessment was performed independently by two of the authors (BE and SC). Shifts were recorded as +1 (an advance), -1 (a delay), or 0 (where the record was too irregular for the direction to be assessed with confidence). Table 1 includes a summary of the direction of shifts of all subjects.

\section{Assessment of predictors}

The analysis consisted of treating the variables measured in the jet lag questionnaire as dependent (outcome) variables, and performing a backwards stepwise multiple regression analysis starting with nine potential predictors (see table 1). The potential predictors included continuous and nominal variables.

Continuous variables were age and the scores for chronotype, languidness, flexibility, and fitness. Any significant positive or negative associations identified in the regression analysis are denoted by + or - respectively in table 3 .

Nominal variables were sex, experience of flying to Australia, flight arrival time (morning or afternoon), and direction of phase adjustment (advance or delay). These nominal or categorical variables were entered as $[0,1]$ indicator variables. The baseline group (allocated a 0 in each of the nominal indicator variables) was the female subjects who had no previous experience of flying to Australia, who arrived in Australia in the morning, and whose direction of phase adjustment was too irregular to be assessed. All other groups (allocated a $\mathrm{l}$ in each of the indicator variables) were compared with the baseline group. Any significant positive or negative differences from the baseline identified in the regression analysis have been denoted by + or - respectively in table 3 .

The analysis was performed separately for each variable, for each day, and, if applicable, for each time of day. Therefore the number of regression analyses carried out was:

jet lag: 1 variable $\times 6$ days $\times 5$ times $=30$;

sleep: 5 variables $\times 5$ days $\times 1$ time $=25$;

fatigue: 1 variable $\times 6$ days $\times 5$ times $=30$;

meals: 3 variables $\times 6$ days $\times 2$ times $=36$; 
Table 2 Median (interquartile range) amount of sleep during the flights (hours)

\begin{tabular}{llll}
\hline & Before stopover & After stopover & Total \\
\hline Group 0* & $5.5(3.0-7.0)$ & $2.5(1.3-4.5)$ & $8.0(5.6-10.0)$ \\
Group 1 $\dagger$ & $1.5(0.8-2.5)$ & $2.8(1.9-3.0)$ & $4.0(2.0-5.0)$ \\
p Valuef & 0.0002 & 0.72 & $<0.0001$ \\
\hline
\end{tabular}

*Arrived in Australia in the early morning, having left the United Kingdom in the evening.

†Arrived in Australia in the late afternoon, having left the United Kingdom in the morning.

$\ddagger$ Significance of the difference between Groups, Mann-Whitney U tests.

bowel activity: 2 variables $\times 6$ days $\times 1$ time $=12$.

Other calculations and statistics will be described as required.

\section{RESULTS}

The amount of data lost during the time in Australia, mainly because of not being able to sample tympanic membrane temperature, was small. The high success rate in obtaining data was due largely to the presence of four of the authors (BE, RG, $\mathrm{RR}$, and TR), who took the tympanic temperatures and reminded the subjects that it was time to fill in their record cards.

\section{Sleep during the flights}

Table 2 summarises the results from the records of sleep during the flights. Subjects in group 0 took about twice as much total sleep as did those from group 1 (about eight hours compared with four hours respectively); this difference was highly significant. When the amounts of sleep in the flights before and after the stopover were considered separately, then there was no significant difference between the two groups in the second flight, but a considerable difference in the first one, group 0 having nearly four times the amount of sleep taken by group 1. It will be noted that the first flight for those in group 0 was taken during the United Kingdom night time (Australian daytime), and the second flight, after the stopover, during the United Kingdom daytime (Australian night time). By contrast, the first flight for group 1 coincided with the United Kingdom daytime (evening and early night in Australia) and the second, with night time in the United Kingdom (the latter half of the Australian night and daytime).

\section{Measurements made in Australia}

When all the regression analyses were considered together, it was noted that the explained variance of each jet lag symptom, identified by the maximum $R^{2}$ criterion, tended to decrease in size with the number of days spent in Australia. This is to be expected as the amount of jet lag and its symptoms has been shown previously to decrease over this period of time. ${ }^{9}$

Table 3 shows the results for the regression analyses. This table includes, for each dependent variable, only those predictors that had a significant effect on at least two occasions in the same direction. We draw attention to the following results.

(1) Jet lag. This was less evident about the middle of the day and at about the time of retiring in older subjects. Considering a difference of 26 years (from 1 SD below the mean age to I SD above it), the effect of age was estimated to be a decrease in jet lag of 1.0 unit at all times. There was also some evidence to suggest that jet lag was felt to be worse in the fitter subjects and in those who had made the journey before. A consistent effect was for jet lag to be less in those who had arrived later in the day, this effect being present at all times of the day except on retiring, both in the first two days after arrival and again on the fifth and sixth days. Also on these last two days of measurement, particularly on rising and at noon, jet lag was worse in those who adjusted by phase advance.

(2) Sleep. There was a slight effect of sex, men tending to go to sleep later. There was also an effect of flexibility of sleeping habits on the ease with which subjects got to sleep and were

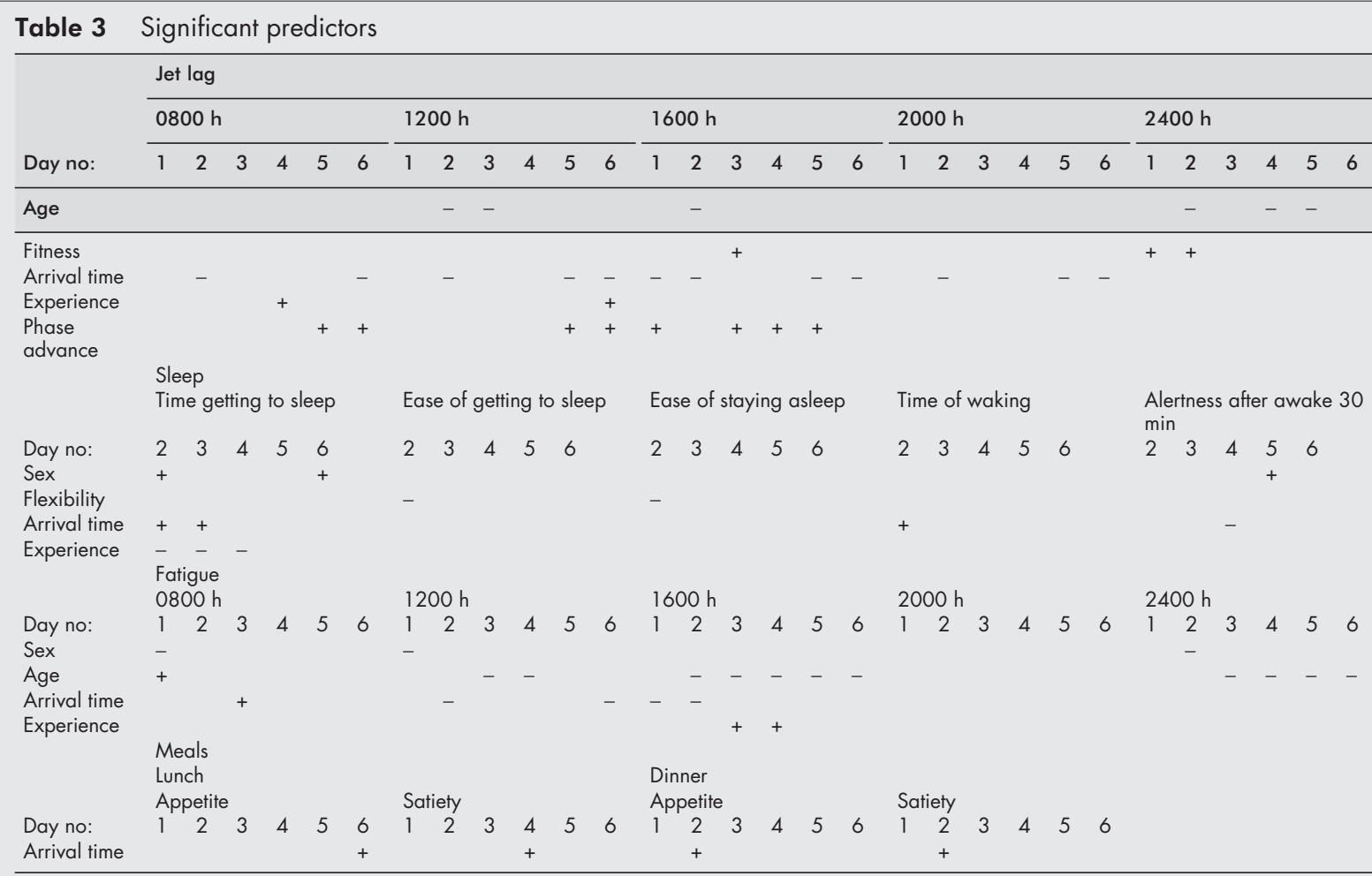


able to stay asleep, these being greater in subjects who had scored lower on the flexibility/rigidity questionnaire. More consistent effects on the time of retiring on the first few nights in Australia were observed in subjects who had arrived in the late afternoon and/or had not flown to Australia before. Those arriving later in the day went to sleep later, as did those for whom this was the first time in Australia.

(3) Fatigue. Men suffered less from fatigue in the first two days after arrival, and there was some evidence to indicate that both those who had flown to Australia before and those who had arrived in the morning showed more fatigue at noon and in the afternoon. The most consistent effect was that older subjects appeared to suffer less from fatigue, particularly in the afternoon and just before retiring. Again, considering the predicted effects of a difference of 26 years, there was a difference of fatigue with age of 0.8 unit at noon, 1.1 units at 1600 $\mathrm{h}$, and 1.4 units on retiring.

(4) Meals. There was some evidence that those who arrived later in the day had better appetites, and yet tended to feel overfull after a meal, but the effects were not seen consistently with regard to the meal or the day of study.

No significant predictors for bowel activity were reliably found.

\section{DISCUSSION}

We consider first the results that did not support predictions based on the scientific literature, namely a lack of predictive power of the personality variables: chronotype, flexibility of habits, and languidness. This lack of power applied, in general, to all the dependent variables considered: sleep, jet lag, fatigue, meals, and bowel function.

The lack of effect of chronotype may be because 78 of the 85 subjects were intermediate type, with only one evening type and seven morning types. It is not possible therefore to compare the present results with studies ${ }^{1134}$ in which separate groups of morning and evening types were investigated. Nevertheless, the present results do indicate the lack of importance of moderate variations in chronotype scorewithin the range of scores encompassing the designation intermediate type-as predictors of the severity of jet lag and its symptoms. The finding that greater flexibility of sleeping habits was significantly associated with a decreased ease of getting to sleep and a decreased ease of staying asleep was unexpected. This effect of flexibility was significant only during the first nocturnal sleep in Australia, and this, coupled with the lack of effect of rigidity of sleeping habits, argues against these variables having an important predictive value in the present group of subjects. Flexibility, rigidity, and chronotype have been found to have predictive power in studies of a population working night shifts, ${ }^{1011}{ }^{1634}$ and this points to there being differences from the current study not only in the change of sleep-wake cycle but also in the type of subject studied. The difference in type of subject may well be because of the exceptionally high motivation of our group; all were determined to make as much use as possible of the time that they spent in Australia. All had specific objectives, whether these were training, coaching, or taking part in a scientific conference, and many had spontaneously expressed the view that jet lag and its associated symptoms were not going to cause them to deviate from these objectives. Such an attitude may also account for the finding that there were no consistent effects of the time zone transition on eating habits or bowel function.

Even so, there was some evidence that the present group of subjects, particularly the athletes, felt slightly thwarted in their aims, there being an increased perception of jet lag in the fitter subjects at the end of the first two days in Australia (compare with the study of Shiota et $a l^{26}$ ). This finding of increased difficulties in our fitter subjects also differs from that found in the study of night workers, ${ }^{24}{ }^{25}$ where increasing the amount of physical activity had a positive effect on the workforce; it differs also from a previous study of Olympic athletes whose circadian rhythms after five time zone shifts westward differed from those of a sedentary control group. ${ }^{35}$ With regard to the night workers who benefited from the increased amount of physical activity, they tended to be rather inactive physically before this intervention. Therefore increasing their activity would not have been comparable to the case of elite athletes, who were routinely far more active and who wished to continue with intensive training schedules. The present results indicate that the daily routine of a high workload in athletes with busy schedules would have rendered them far more prone to any negative effects of time zone travel. Furthermore, the method of self rating fitness used in this study $^{29}$ may lose sensitivity when applied across heterogeneous groups.

Men showed a slight tendency to go to bed later and, in the first days in Australia, to record less fatigue; to what extent these results reflect differences in the amount of "socialising" and the presentation of a "macho" image respectively cannot be ascertained.

In contrast with the variables discussed so far, which only rarely, if at all, acted as significant predictors, there were others that seemed more powerful in this respect. These included age, experience, and arrival time; they can form the basis of advice to travellers.

The older subjects showed less jet lag and fatigue, particularly in the middle of the day and just before retiring. This result argues against the hypothesis that younger subjects are more flexible in their sleeping habits and better able to deal with the effects of a time zone transition; instead, it argues for the idea that older subjects are better able to "pace themselves", a result that has been found previously. ${ }^{18}$ In addition, however, as it was the athletes who tended to be the younger subjects in the present study, the finding may stress that any ill effects, which would tend to interfere with their training regimens, would be more noticed by them.

Those who had not travelled to Australia before showed slightly less jet lag and fatigue, and went to sleep later on the first three nights after arrival. One interpretation of this is that the undoubted excitement associated with a long distance journey to a continent on the other side of the world-tending to result in later nights and any negative symptoms of jet lag being ignored-begins to be tempered on subsequent trips.

Subjects who arrived in Australia in the late afternoon went to sleep later on the first two nights after arrival, and tended to report less jet lag and fatigue on the first two days in Australia. This was in spite of having taken less sleep on the plane, particularly during the first flight (table 2 ). These results do not support the view that the amount of sleep taken during the journey is critical. Another difference between the two groups must be sought therefore. One possibility is as follows. On going to bed for their first night's sleep in Australia, those who had arrived in the late afternoon (and set off from the United Kingdom in the morning) had last taken a full sleep in a bed over 30 hours previously, and had managed about four hours sleep in total during the flights; by contrast, those who had arrived in Australia in the early morning (and had left the United Kingdom in the evening) had, by the time they went to sleep at night, not taken a full sleep in a bed for about 50 hours previously, even though they had managed about eight hours sleep in total on the flights. That is, the amount of sleep deprivation suffered by the morning arrivals in Australia was considerably greater, even taking into account the greater amount of sleep taken by them on the flights and the possibility that those leaving the United Kingdom in the morning (and arriving in Australia in the late afternoon) may have had to get up earlier than normal before their flight and so start the journey with some degree of sleep loss.

The present results indicate that the effects of such sleep deprivation, coupled with any sleep problems resulting from 
the change in local time, lasted for a couple of days. These results are difficult to compare with those from the scientific literature. In most other studies of sleep deprivation (see, for example, the study of Meney $e t a l^{36}$ ), sleep loss has not been coupled with a simultaneous time zone transition. In studies of sleep in aircrew in which a time zone transition was involved (for example, those of Gardner $e^{~} a^{37}$ and Lowden and Akerstedt $^{38}$ ), the times of sleep tended to be determined by work schedules and/or attempts to retain home time; even so, recovery from sleep loss takes more than one night. In studies of sleep loss during night work also, it is generally found that there is not an immediate recovery at the end of a series of night shifts, and that the first "recovery sleep" does not allow complete recuperation. ${ }^{59} 40$

When the last few days of the study are considered, any effects observed are unlikely to have been a direct result of sleep loss during the flight, but may instead be related to the process of phase adjustment. With regard to this, it was found that those who adjusted by phase advance suffered more jet lag in the later part of the study (table 3), particularly in the first part on the waking day. This may be explained as follows: on arrival in Australia, the minimum core temperature would have been about 1500 local time (equivalent to 0500 United Kingdom time). Adjustment by phase advance would have caused this temperature minimum to advance through the afternoon and then the morning; accepting that the temperature minimum is normally associated with most fatigue and least mental and physical activities, ${ }^{41}{ }^{42}$ then this adjustment by phase advance would have caused the observed symptoms. If, by contrast, adjustment had been by phase delay, then the temperature minimum would have passed from the afternoon to the evening, a time of relaxation. It seems less likely that this would have been recorded as an undesirable side effect of the time zone transition, that is, as jet lag.

The direction of adjustment of the body clock is believed to depend on exposure to light and darkness, ${ }^{6}{ }^{43}$ particularly during the flight and the first day or so in Australia. Adjusting to the new local time by a phase advance would have required an avoidance of bright light until about 1300, and seeking it from about 1500 onwards, on the first day, with the time of seeking light becoming progressively earlier on subsequent days. It is unclear whether subjects attempted to adopt such a routine; even if they had, it is doubtful whether their schedule in Australia would have allowed them to adhere to it strictly. Moreover, we did not record light exposure in our subjects; therefore any link between light exposure in Australia and the direction of adjustment of the body clock cannot be ascertained. However, it is clear that, with time zone transitions as large as the present one, phase adjustment either by a delay (of 14 hours) or an advance of 10 hours is possible. In both cases, active management of exposure to light is desirable, the choice of the preferred direction of adjustment being left to the travellers, depending on their commitments after arrival.

In summary, the results from this field study of jet lag and its symptoms focus attention away from personality variables and towards factors such as the organisation of the journey and the attitude of the travellers, particularly if they are highly motivated. This is a position that would hold for athletes and sports persons journeying to another continent for training or for an important competition or game. There would seem to be an advantage in trying to arrange for the flight times to be such that the amount of time spent before being able to take a full sleep in a bed at the new night time is made as short as possible. In addition, many of the results can be interpreted to indicate that adopting a busy schedule in the new time zone is advantageous, provided that it is understood that jet lag will result in the quality of performance being reduced temporarily. ${ }^{5}{ }^{8}$ There also appears to be, for an eastwards time zone transition of this magnitude, an argument against promoting adjustment of the body clock by phase advance (by

\section{Take home message}

Even for subjects with a high degree of motivation, flying from the United Kingdom to Sydney (Australia) causes several negative effects on sleep, mood, and alertness, collectively known as jet lag. The symptoms are less in subjects with better travel arrangements (having to stay awake less time), in older subjects, and in those with experience of travel rather than in subjects with a particular chronotype or greater flexibility of habits. These results stress the importance of appropriate advice for travellers who wish to perform at their best in the new time zone as soon as possible after arrival.

suitably timing exposure to, and avoidance of, bright light), because such an adjustment means that the times of worst performance advance through the afternoon and morning in the new time zone, times when athletes would wish their performance to be as near its peak as possible. For travellers to adopt the alternative phase delay strategy would require that they be given detailed guidelines for timing of sleep and waking, and exposure to and avoidance of light.

\section{ACKNOWLEDGEMENT}

The authors would like to thank the subjects, the British Olympic Association, and British Airways for help with this project.

\section{Authors' affiliations}

J Waterhouse, B Edwards, S Carvalho, G Atkinson, P Buckley, T Reilly, Research Institute for Sport and Exercise Sciences, Liverpool John Moores University, Liverpool, UK

A Nevill, School of Sport, Performing Arts and Leisure, University of

Wolverhampton, Walsall, UK

R Godfrey, R Ramsay, British Olympic Medical Centre, Northwick Park, Middlesex, UK

\section{REFERENCES}

1 Graeber $\mathbf{R}$. Alterations in performance following rapid transmeridian flight. In: Brown F, Graeber R, eds. Rhythmic aspects of behavior. London: Lawrence Erlbaum Associates, 1982:173-212.

2 Winget C, de Roshia C, Markley C, et al. A review of human physiological and performance changes associated with desynchronosis of biological performance. Aviat Space Environ Med 1984;55: 1085-96.

3 Tsai T-H, Okumura M, Yamasaki M, et al. Simulation of jet lag following a trip with stopovers by intermittent schedule shifts. J Interdiscipl Cycle Res 1988;19:89-96.

4 Redfern P. "Jet-lag": strategies for prevention and cure. Human Psychopharmacology 1989;4:159-68.

5 Reilly T, Atkinson G, Waterhouse J. Biological rhythms and exercise. Oxford: Oxford University Press, 1997.

6 Waterhouse J, Reilly T, Atkinson G. Jet-lag. Lancet 1997;350: $1611-16$.

7 Cho K, Ennaceur A, Cole J, et al. Chronic jet lag produces cognitive deficits. J Neurosci 2000;20:RC66-70

8 Youngstedt S, O'Connor $\mathrm{P}$. The influence of air travel on athletic performance. Sports Med 1999;28:197-207.

9 Waterhouse J, Edwards B, Nevill A, et al. Do subjective symptoms predict our perception of jet-lag? Ergonomics 2000;43:1514-27.

10 Kerkhof G. Inter-individual differences in the human circadian system: a review. Biol Psychol 1985;20:80-112.

11 Harma M. Individual differences in tolerance to shiftwork: a review. Ergonomics 1993;36:101-9.

12 Preston F, Bateman S, Short R, et al. Effects of flying and of time changes on menstrual cycle length and on performance in airline stewardesses. Aerospace Medicine 1973;44:438-43.

13 Harma $M$, Laitinen J, Partinen $M$, et al. The effect of four-day round trip flights over 10 time zones on the circadian variation of salivary melatonin and cortisol in airline flight attendants. Ergonomics 1994;37: 1479-89.

14 Reilly T, Atkinson G, Waterhouse J. Endurance performers and time-zone shifts. In: Shephard R, Astrand P-O, eds. Endurance in sport, 2nd ed. Oxford: Blackwells, 2000:639-50.

15 Gander P, Nguyen D, Rosekind M, et al. Age, circadian rhythms, and sleep loss in flight crews. Aviat Space Environ Med 1993;64:189-95. 16 Folkard S, Monk T, Lobban M. Towards a predictive test of adjustment to shift work. Ergonomics 1979;22:79-91.

17 Moline M, Pollack C, Monk T, et al. Age-related differences in recovery from simulated jet lag. Sleep 1992;15:28-40. 
18 Monk T, Buysse D, Carrier J, et al. Inducing jet-lag in older people: directional asymmetry. J Sleep Res 2000;9:101-16.

19 Volk S, Dyroff J, Georgi K, et al. Subjective sleepiness and physiological sleep tendency in healthy young morning and evening subjects. J Sleep Res 1994:3:138-43.

20 Kerkhof G, van Dongen H. Morning-type and evening-type individuals differ in the phase position of their endogenous circadian oscillator. Neurosci Lett 1996:218:153-6.

21 Duffy J, Dijk D, Hall E, et al. Relationship of endogenous circadian and melatonin and temperature rhythms to self-reported preference for morning and evening activity in young and older people. Journal of Investigative Medicine 1999;47:141-50.

22 Baehr E, Revelle W, Eastman C. Individual differences in the phase and amplitude of the human circadian temperature rhythm: with an emphasis on morningness-eveningness. J Sleep Res 2000;9:117-27.

23 Barton J, Spelten E, Totterdell P, et al. The Standard Shiftwork Index: a battery of questionnaires for assessing shiftwork-related problems. Work and Stress 1995;9:4-30

24 Harma $M$, Ilmarinen J, Knauth $P$, et al. Physical training intervention in female shift workers. I. The effects of intervention on fitness, fatigue, sleep, and psychomotor symptoms. Ergonomics 1988:31:39-50.

25 Harma $M$, Ilmarinen J, Knauth $P$, et al. Physical training intervention in female shift workers. II. The effects of intervention on the circadian rhythms of alertness, short-term memory, and body temperature. Ergonomics 1988;31:51-63.

26 Shiota M, Sudo M, Ohshima M. Using outdoor exercise to decrease jet lag in airline crewmembers. Aviat Space Environ Med 1996;67: 11 155-60

27 van Someren E, Lijzenga C, Mirmiran M, et al. Long-term fitness training improves the circadian rest-activity rhythm in healthy elderly males. J Biol Rhythms 1997; 12:146-56.

28 Reilly T. Environmental stress. In: Reilly T, ed. Science and soccer London: E and FN Spon, 1996:201-24

29 Lamb K, Brodie D. Leisure time physical activity as an estimate of physical fitness: a validation study. J Clin Epidemiol 1991;44:41-52.
30 Smith C, Reilly C, Midkiff K. Evaluation of three circadian rhythm questionnaires with suggestions for an improved measure of morningness. J Appl Psychol 1989;74:728-38.

31 Minors D, Waterhouse J. Anchor sleep as a synchronizer of rhythms on abnormal routines. Int J Chronobiol 1981;7:165-88.

32 Edwards B, Atkinson G, Waterhouse J, et al. Use of melatonin in recovery from jet-lag following an eastward flight across 10 time-zones. Ergonomics 2000;43:1501-13.

33 Minors D, Waterhouse J. Masking in humans: the problem and some attempts to solve it. Chronobiol Int 1989;6:29-53.

34 Costa G, Lievore F, Casaletti G, et al. Circadian characteristics influencing interindividual differences in tolerance and adjustment of shiftwork. Ergonomics 1989:32:373-85.

35 Reilly T, Atkinson G, Budgett R. Effects of temazepam on physiological and performance variables following a westerly flight across five time zones. J. Sports Sci 1997;15:62.

36 Meney I, Waterhouse J, Atkinson G, et al. The effect of one night's sleep deprivation on temperature, mood, and physical performance in subjects with different amounts of habitual physical activity. Chronobiol Int 1998:15:349-63.

37 Gander P, Myhre G, Graeber R, et al. Adjustment of sleep and the circadian temperature rhythm after flights across nine time zones. Avia Space Environ Med 1989;60:733-43.

38 Lowden A, Akerstedt T. Retaining home-base sleep hours to prevent jet lag in connection with a westward flight across nine time zones. Chronobiol Int 1998;15:365-76.

39 Knauth P, Rutenfranz J, Herrmann G. Re-entrainment of body temperature in experimental shift-work studies. Ergonomics 1978;21:775-83.

40 Akerstedt T. Work hours, sleepiness and accidents. Introduction and summary. J Sleep Res 1995;4(suppl 2): 1-3

41 Folkard S. Circadian performance rhythms: some practical and theoretical considerations. Philos Trans R Soc Lond B 1990;327:543-53.

42 Monk T, Carrier J. Speed of mental processing in the middle of the night. Sleep 1997:20:399-401.

43 Boulos Z, Campbell S, Lewy A, et al. Light treatment for sleep disorders: consensus report. 7. Jet-lag. J Biol Rhythms 1995;10:167-76.

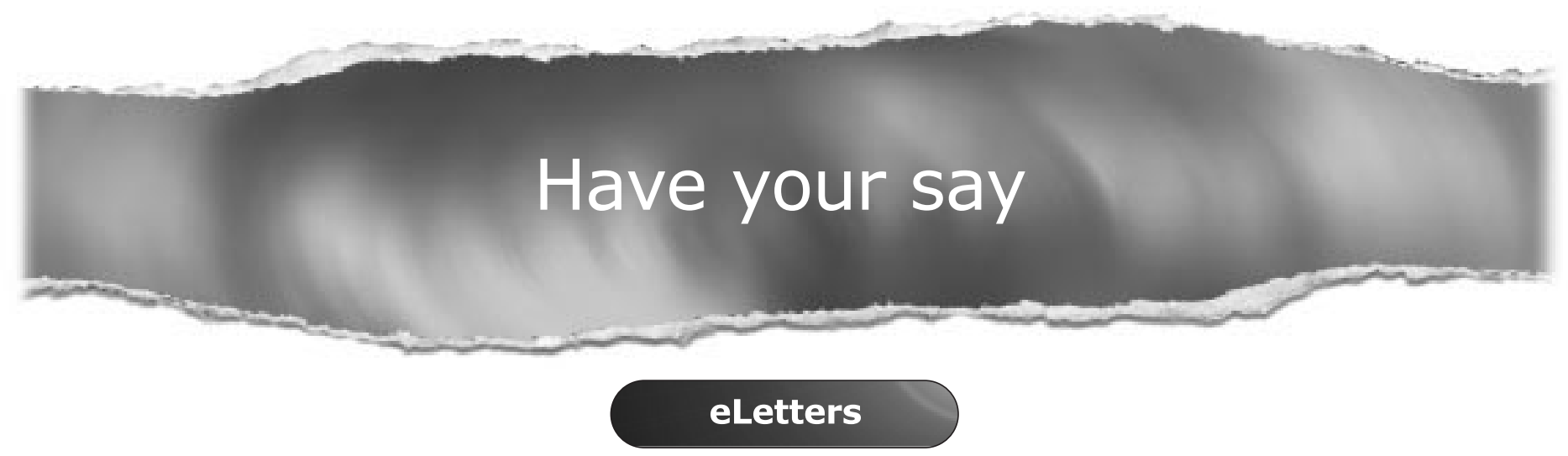

If you wish to comment on any article published in the British Journal of Sports Medicine you can send an eLetter using the eLetters link at the beginning of each article. Your response will be posted on British Journal of Sports Medicine online within a few days of receipt (subject to editorial screening).

\section{www.bjsportmed.com}

